University of Nebraska - Lincoln

DigitalCommons@University of Nebraska - Lincoln

Architectural Engineering -- Faculty Publications

Architectural Engineering and Construction,

Durham School of

2012

\title{
An adaptive utility interactive photovoltaic system based on a flexible switch matrix to optimize performance in real-time
}

\author{
Mahmoud Alahmad \\ University of Nebraska - Lincoln, malahmad2@unl.edu \\ Mohamed Amer Chaaban \\ University of Nebraska-Lincoln, mchaaban@unomaha.edu \\ Siu Kit Lau \\ University of Nebraska-Lincoln, slau3@unl.edu \\ Jonathan Shi \\ University of Florida, Gainesville, jshi3@ufl.edu \\ Jill Neal \\ US Environmental Protection Agency, Cincinnati, OH, neal.jill@epa.gov
}

Follow this and additional works at: https://digitalcommons.unl.edu/archengfacpub

Part of the Architectural Engineering Commons, Controls and Control Theory Commons, Electromagnetics and Photonics Commons, and the Power and Energy Commons

Alahmad, Mahmoud; Chaaban, Mohamed Amer; Lau, Siu Kit; Shi, Jonathan; and Neal, Jill, "An adaptive utility interactive photovoltaic system based on a flexible switch matrix to optimize performance in realtime" (2012). Architectural Engineering -- Faculty Publications. 59.

https://digitalcommons.unl.edu/archengfacpub/59

This Article is brought to you for free and open access by the Architectural Engineering and Construction, Durham School of at DigitalCommons@University of Nebraska - Lincoln. It has been accepted for inclusion in Architectural Engineering -- Faculty Publications by an authorized administrator of DigitalCommons@University of Nebraska Lincoln. 


\title{
An adaptive utility interactive photovoltaic system based on a flexible switch matrix to optimize performance in real-time
}

\author{
Mahmoud Alahmad $^{\text {a,* }}$, Mohamed Amer Chaaban ${ }^{\mathrm{b}}$, Su kit Lau ${ }^{\mathrm{a}}$, Jonathan Shi ${ }^{\mathrm{c}}$, Jill Neal ${ }^{\mathrm{d}}$ \\ ${ }^{a}$ Durham School of Architectural Engineering and Construction, University of Nebraska-Lincoln, Omaha, NE 68182, USA \\ ${ }^{\mathrm{b}}$ University of Nebraska-Lincoln, Omaha, NE 68182, USA \\ ${ }^{\mathrm{c}}$ University of Florida, Gainesville, FL 32611, USA \\ ${ }^{\mathrm{d}}$ US Environmental Protection Agency (US EPA), Cincinnati, Ohaio 45268, USA
}

Received 12 August 2011; received in revised form 22 November 2011; accepted 27 December 2011

Available online 28 January 2012

Communicated by: Associate Editor Arturo Morales-Acevedo

\begin{abstract}
Reconfigurable architectures are of great interest to system designers to improve the system's operation and efficiency. In this paper, we propose an adaptive utility interactive photovoltaic (PV) system based on a novel Flexible Switch array Matrix topology. This proposed system maximizes the generated power in real-time in response to operational conditions such as shading, soiling, mismatches, and module failure among others. The proposed system is a compromise in the utilization of power conditioning equipment to maximize energy capture and system efficiency. Simulation results demonstrate an average $13 \%$ improvement in efficiency when compared with the central inverter topology performance. A prototype system has been designed and tested. The experimental results validate the proposed topology and its benefits for a wide range of applications.
\end{abstract}

(C) 2012 Elsevier Ltd. All rights reserved.

Keywords: Adaptive systems; Photovoltaic power systems; Photovoltaic cells; Utility interactive system; Central inverter topology; Inverter

\section{Introduction}

The world energy consumption is 10 terawatts (TW) per year and by 2050, it is projected to be about $30 \mathrm{TW}$ (Razykov et al., 2011). Due to the environmental issues caused by the production of this energy and specifically electricity from fossil fuel resources, there is currently a growing trend towards the more widespread use of solar energy systems and particularly photovoltaic (PV) systems. In 2009, the world PV production increased to $10.66 \mathrm{GW}$ (Razykov

\footnotetext{
* Corresponding author. Address: Durham School of Architectural Engineering and Construction, University of Nebraska-Lincoln, 206A, PKI, 1110 South 67th Street, Omaha, NE 68182, USA. Tel.: +1 402554 3527 (office), +1 4022135152 (mobile).

E-mail addresses: malahmad2@unl.edu (M. Alahmad),mchaaban@ unomaha.edu (M.A. Chaaban), slau@mail.unomaha.edu (S.kit Lau), jshi3 @ufl.edu (J. Shi), neal.jill@epa.gov (J. Neal).
}

et al., 2011). However, the wider PV system implementation is still hampered by the relatively high cost and modest efficiency. Despite the low efficiency of PV systems, PV energy has great potential for use in several applications including residential and commercial buildings, electrical vehicles, water pumping systems, as well as rural applications. PV systems require various components to conduct, control, convert, store, and utilize the energy generated by the PV system. For the purposes of this paper, a module consists of connected PV cells in one frame, and an array is a complete PV unit consisting of connected modules with structural support (Dunlop, 2010; Rashid, 2007). Each PV array is comprised of parallel connection strings. Each string consists of multiple series connection PV modules that provide the required voltage of the array. These modules are usually connected to the grid via a Maximum Power Point Tracker (MPPT) that maximizes the output power of the 


\section{Nomenclature}

AC alternating current

CMOS complementary metal-oxide-semiconductor

DC direct current

DC/DC direct current/direct current

EAR Electrical Array Reconfiguration

EPVS Elastic Photovoltaic Structure

FSM Flexible Switch array Matrix

I current

MEMS MicroElectro-Mechanical Systems

MPP Maximum Power Point

MPPT Maximum Power Point Tracker

MPV main PV string
NMOS N-type metal-oxide-semiconductor

PMOS P-type metal-oxide-semiconductor

PV photovoltaic

$\mathrm{S}_{\text {by }} \quad$ bypass switches

$\mathrm{S}_{\mathrm{Pu}} \quad$ positive terminal connection switches

$\mathrm{S}_{\mathrm{Pd}} \quad$ negative terminal connection switches

$\mathrm{S}_{\mathrm{Sr}} \quad$ series connection switches

SPV sub-PV string

STC standard test conditions

TW terawatts

V voltage array as an integral part of the inverter. The components are configured based on the load usage, load type, solar resources, and other factors. In general, the configurations fall into four main types: Stand-alone systems (off-grid); utility interactive systems (grid-connected); bimodal systems; and hybrid systems. The stand alone system can be configured in a variety of ways. It can be configured as a direct coupled system in which the PV is directly connected to the load, as a self regulated system in which energy storage (the battery) is added but with no active control to protect it except through careful system design, or as a charge controlled system in which a charge controller is added for battery management. The utility interactive system consists of PV array and power conditioning units that operate in parallel to the grid and connect to the utility. The bimodal system is a system that can operate as a stand-alone or as a utility interactive system. The hybrid system is a system that incorporates multiple distributed energy sources such as the PV, wind turbine, battery banks, and engine generator depending on their availability and cost (Dunlop, 2010; Rashid, 2007).

The PV system interface, connections, and the configuration of the components are vital to achieving a system performance to encourage more widespread PV installation. The performance of the system not only depends on operational conditions such as solar irradiance, location, shadowing, high temperatures, or the efficiency degradation of the sub-components, but it is also strongly dependent on the PV system configuration. Notably, dissimilarity in the output of PV modules can occur in the PV array by operating at their own Maximum Power Point (MPP). Reasons for this dissimilarity may include shading across some modules and manufacturing differences in the $I-V$ characteristics of each module. Since each PV module has a different MPP, the dissimilarity results in the reduction of the total harvested power (Chew and Siek, 2010).

Active research to improve the efficiency of PV systems is focusing on the cell level through the development of new semiconductor structures and at the system level by tracking the optimal operational conditions and proposing novel topologies to achieve a greater energy capture. This is due to the fact that during operation, the system level efficiency is impacted by internal and external factors including mismatch, diodes and connections, DC wiring, AC wiring, soiling, system availability, shading, sun-tracking, age, inverter and transformer and PV module nameplate DC rating (PVWatts Online Derate Calculator). For example, in Massi Pavan et al. (2011), an 8-10\% of the power loss registered can be removed by cleaning the arrays. Furthermore, a $6.9 \%$ of losses for a plant built on a sandy soil and a $1.1 \%$ for plant built on a more compact soil has been found by conducting a study on a 1-MWp PV system in Italy (Massi Pavan et al., 2011). To optimize the capture of energy, the tilt angle is investigated in Beringer et al. (2011). It is recommended that the yearly optimum energy capture tilt angle should be within $10^{\circ}$ of the latitude. However, an experimental study in Germany, found that a nearly irrelevant difference of the yearly performance of solar cells at various tilt angles. However, the paper states that additional testing must be conducted before abandoning the tilt angle. In Li et al. (2011), shading of partial PV arrays is demonstrated to cause multiple peaks resulting in local peaks that if selected will result in greatly reducing the efficiency of PV systems. Finally, in AlRashidi et al. (2011), Zhu et al. (2011) and Saloux et al. (2011) techniques to determine the $I-V$ characteristics of solar cells are discussed. This information is very valuable for PV designers to determine the system performance and comparison with experimental results as discussed in this paper.

With respect to the system level research, a modular DC/ DC converter topology is proposed in Chew and Siek (2010), to reduce the number of DC/DC components that track the MPP used in stand-alone PV systems. This topology requires all PV modules to work in parallel which may not be applicable for large scale installations. In Nguyen and Lehman (2008), a reconfiguration at the cell level is discussed to address the shadowing effect and increase the output power through the addition of external reconfigurable cells. In Chang(2003) and Sherif and Boutros (2002), dissimilar cells are matched through reconfiguration to improve 
the system efficiency. Improvements to the system are accomplished through the reconfiguration of a large number of switches and sensors at the cell level. In Velasco et al. (2009), an Electrical Array Reconfiguration (EAR) is proposed at the module level using a switching matrix that can change the position of the modules to achieve better matching between similarly illuminated PV modules. The system is used to maximize the available DC power by matching modules that have similar operational conditions. In Auttawaitkul et al. (1998), reconfiguration is proposed for an electric vehicle to increase its power output and operate the load at the desired conditions to improve the load efficiency. During acceleration, for example, the engine requiring additional torque is supplied by reconfiguring the PV in parallel to increase the current output. In Salameh and Liang (1990), the optimum switching points for the array reconfiguration controller is discussed according to the insolation conditions.

In this paper, we propose a novel adaptive utility interactive system to increase the efficiency of PV systems through the integration of a flexible switch matrix that will establish an interface between PV modules and the power conditioning units. Section 2 provides background information on existing PV system configurations. Section 3 introduces the proposed topology and its operation.
Section 4 presents simulation and analysis of the proposed topology along with an experimental prototype system that has been designed and tested to validate the results. Finally, Section 5 provides a summary and conclusion.

\section{Existing PV system configurations}

Reconfigurable architectures are of great interest to system designers. This interest is gaining more momentum as technological advances and improvements to system components become more modular and allow for greater design flexibility and innovation. The utility interactive system, the simplest system in terms of design, is configured with added components to improve its efficiency. Currently the following configurations are found in the literature: Central-inverter; multi-DC/DC-central inverter; string inverter; team inverter and module inverter configuration. The following paragraph will provide a brief description of each configuration.

The central inverter system consists of one inverter and several strings each with a fixed number of series connected PV modules, as shown in Fig. 1a. The strings are connected to a common combiner box then to a central inverter that converts the power from DC to AC to supply the grid. This configuration cannot correctly track the MPP for the whole

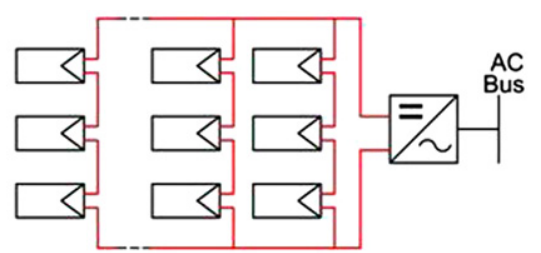

(a) Central-Inverter Configuration

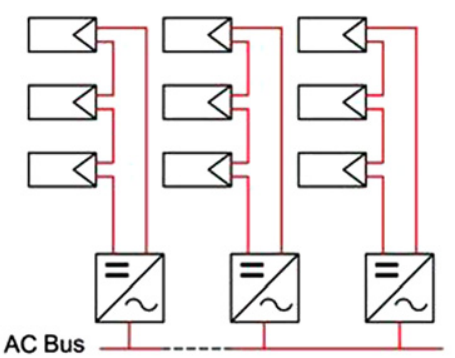

(c) String Inverter Configuration

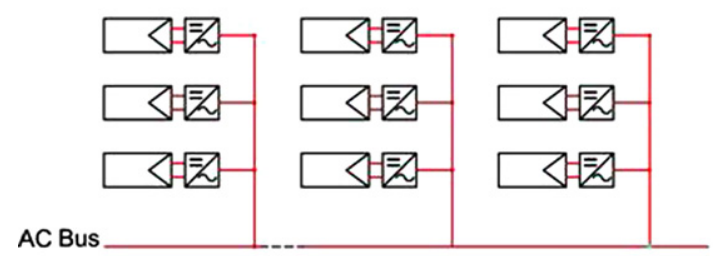

(e) Module inverter configuration

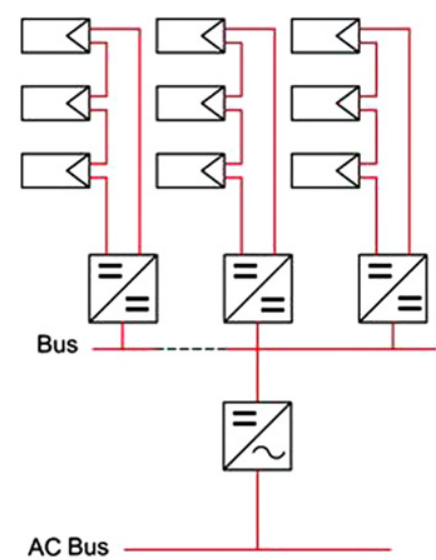

(b) Multi-DC/DC- Central Inverter Config.

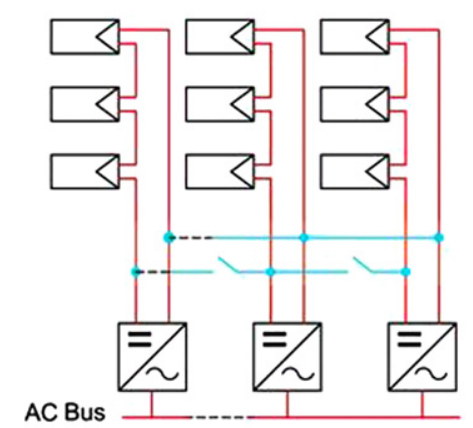

(d) Team-inverter configuration

Fig. 1. Existing PV system configurations (Chaaban and Alahmad, 2010). 
array (Dunlop, 2010; Myrzik and Calais, 2003; Kjaer et al., 2005). This is because each string has its own MPP according to the operational conditions and shadowing effect. The Multi DC/DC-central inverter system configuration, shown in Fig. 1b, improves the performance of the central inverter system during shadowing conditions by adding a DC/DC converter to each string. The advantage of this configuration is that it has the ability to follow the MPP of each string independently (Dunlop, 2010; Myrzik and Calais, 2003; Kjaer et al., 2005). In the Multi-String inverter configuration, shown in Fig. 1C, each string has its own inverter and all inverters operate in parallel to supply the load. This system increases the system efficiency, but with additional cost (Dunlop, 2010; Myrzik and Calais, 2003; Kjaer et al., 2005). The team-inverter configuration, shown in Fig. 1d, uses controllable switches to connect the parallel string inverters according to the solar insolation (Myrzik and Calais, 2003). The system connects the proper number of strings in parallel to a specific number of parallel inverters, thus maximizing the efficiency of the connected inverters. During low irradiance conditions, the generated energy from each string in the PV system does not match the optimal working efficiency of the inverters. Therefore, combining parallel strings will increase the generated energy to match the optimal operating point of the selected inverter(s). Finally, in the module-inverter or (micro-inverter) system, shown in Fig. 1e, each single module is connected to its own inverter that can individually operate near the module's MPP. This effectively increases the efficiency of the whole system (Dunlop, 2010; Sherif and Boutros, 2002; Myrzik and Calais, 2003). A 5-20\% more energy can be harvested over the life of the system using this topology (Lalonde, 2011).

\section{The proposed adaptive utility interactive system}

A Flexible Switch array Matrix (FSM) is presented in Alahmad and Hess $(2008,2010)$. This matrix is integrated with PV modules to form the Elastic Photovoltaic Structure (EPVS). In this integration, full flexibility and fault tolerant design is achieved by connecting adjacent and non-adjacent modules for the purpose of increasing energy capture in real time during shading, soiling, mismatches or other effects. EPVS is combined with a single central inverter and a DC/DC converter to provide an adaptive utility interactive system as shown in Fig. 2. This proposed system is a compromise between the topologies presented in Fig. 1a-d and offers a flexible connection to rearrange the PV modules according to the operational conditions in real-time. The system consists of: an EPVS comprising the PV modules and the FSM; central inverter; DC/DC converter; and a power management system (controller). Using the EPVS, the configuration that most efficiently extracts the maximum potential power from the PV is selected. Under normal conditions, the topology operates as a central inverter topology (Fig. 1a) with the DC/DC converter isolated from the system (i.e. not connected). However, if voltage and/or

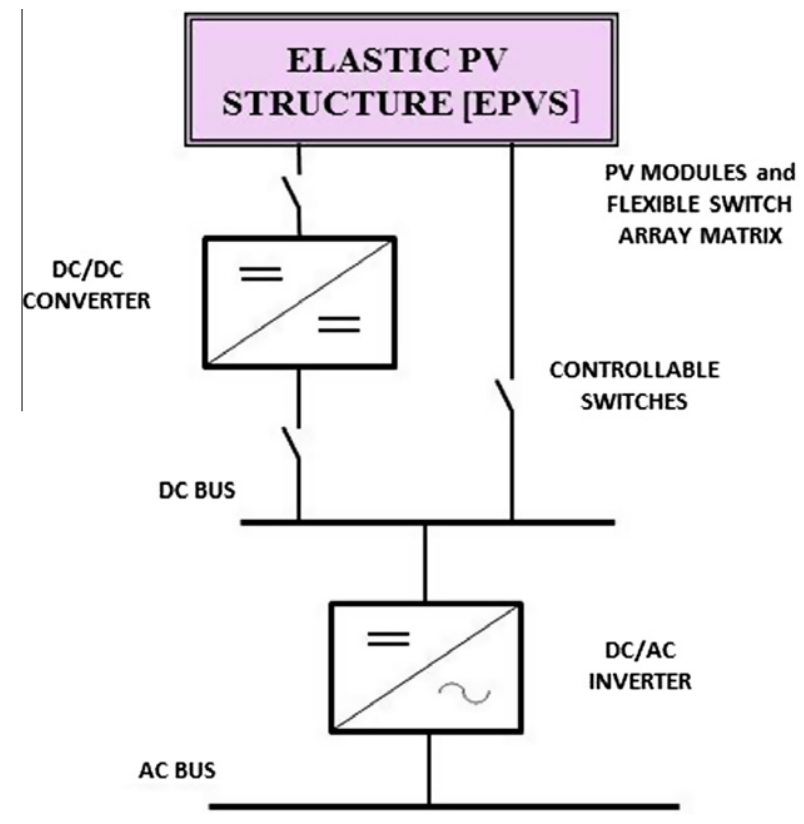

Fig. 2. Proposed adaptive utility interactive system.

current mismatches occur across adjacent and non-adjacent modules, the EPVS system will be reconfigured to maximize energy capture. By employing reconfiguration and management, complete strings are formed and connected directly to the inverter and the DC/DC converter is utilized (if needed) to connect the remaining modules (excluding the effected modules) in a partial string to connect to the inverter. In doing so, the system achieves the best configuration to capture the most energy that otherwise might be eliminated due to the static configuration of the traditional configurations.

For example, significant reduction of the generated power from the solar PV array occurs when shading occurs across some PV modules, leading to extra losses (Chaaban and Alahmad, 2010). The hot spot in the shaded module is capable of sustaining permanent damage at the cell level. The traditional method to reduce the effect of shading on the module is to incorporate a bypass diode. This method usually requires the integration of bypass diodes at the cell or module level, and thus results in extra costs and power losses. Furthermore, multiple peaks become present in the system's output power curve leading to additional system losses. An optimal MPPT must both follow the global peak of the power curve and avoid the local peaks (Esram and Chapman, 2007; Saiju, 2008). Another example is the mismatching effect of unequal voltage between strings that occur because of dissimilarity between the voltages of the modules in different strings (Chew and Siek, 2010; Kjaer et al., 2005) leading to reduce system efficiency. The proposed system addresses both issues along with other effect. Hence, eliminating additional required diodes and utilizing simpler MPPT systems. As will be demonstrated in later sections, Figs. 6 and 7 provide a comparison of the output curves of the adaptive and traditional fixed systems during shading conditions. The following subsections will describe 
the system, its benefits, and operation under different conditions.

\subsection{The Elastic Photovoltaic Structure (EPVS) topology}

The EPVS system consists of the Flexible Switch array Matrix (FSM) and the PV modules. The FSM is a topology customizable to fit many applications and consists of an up to an " $N$ " number of interrelated devices (PV modules in this application); up to an " $M$ " number of controllable elements; and internal and external buses to connect the devices to two external terminals. The devices, the heart of the matrix, can be combined in different configurations to provide greater output, capacity or range than that provided by one single element. Typical devices include: energy storage; power sources; resistors; capacitor; Light Emitting Diodes; memory elements; renewable energy, and other devices. The controllable elements are switches that can be controlled for on/off operation to provide features for connecting adjacent devices adaptively including parallel, series, or parallel/series connection and selective device isolation. Examples of switches include relays, contactors, bulk and integrated NMOS, PMOS and CMOS transistors, and MEMS switches, depending on the particular technology and application. The internal and external buses are configured based on the specific devices used in the topology and on what is being implemented to connect to the external terminals.

The FSM topology is integrated with PV modules to form the EPVS as shown in Fig. 3. The topology, during operation, sorts the system's strings into two categories: the main PV string (MPV), which forms complete strings with the proper number of modules, and the sub-PV string (SPV), which forms a partial string that consists of the remaining PV modules that do not meet the required number to form an MPV. There are two different types of buses to connect the MPV and SPV to the inverter and the DC/ DC converter: the string-buses that connect the MPV strings to the central inverter, and the DC/DC-buses that connect the SPV modules to the DC/DC converter. Under normal conditions, there are no partial strings and hence the DC/DC bus and converter is not utilized. The switches are categorized according to their function in the EPVS. The $\left(\mathrm{S}_{\mathrm{sr}}\right)$ are switches used to achieve the series connection between the PV modules. The series connection occurs between adjacent/nonadjacent modules, that is, for example, between the first and the third module using switch $\mathrm{S}_{\text {by } 2}$ in addition to switch $\mathrm{S}_{\mathrm{sr} 1}$. The $\left(\mathrm{S}_{\mathrm{by}}\right)$ are switches that allow modules to be removed (bypassed) from the configuration. In the last example, the connection between the first and the third module is achieved using $\left(\mathrm{S}_{\text {by } 2}\right)$ bypassing the second module. The $\left(\mathrm{S}_{\mathrm{pu}}\right)$ are switches that connect the positive terminal of the module to the positive terminal of the buses. Activating any of the switches will establish the end of a complete string (i.e. an MPV). The $\left(\mathrm{S}_{\mathrm{pd}}\right)$ are switches that connect the negative terminal of the module to the negative terminal of the buses. The formed MPV and SPV (if needed) based on real-time conditions are then connected to the inverter and DC/DC converter via the main switches at the main terminals. This allows the terminals/output of the EPVS to be connected to the inverter and DC/DC converter simultaneously.

The number of switches in the EPVS depends on the number of modules in the system. Each module requires four switches and each bus requires two switches to connect the MPVs and SPV to the inverter and the DC/DC converter; hence:

$N_{\text {sw }}=4\left(N_{\text {mod }}\right)+2(\mathrm{dc})+2($ inv $)$

where $N_{\text {sw }}$ is the number of switches required for the adaptive PV system; $N_{\text {mod }}$ is the number of modules in the PV array; 2(dc) and 2(inv): are for the inverter and DC/DC converter switches.

\subsection{Illustrative example describing the adaptive utility interactive system operation}

A 9-module adaptive utility interactive system is used to illustrate the adaptive nature of the proposed system. In this

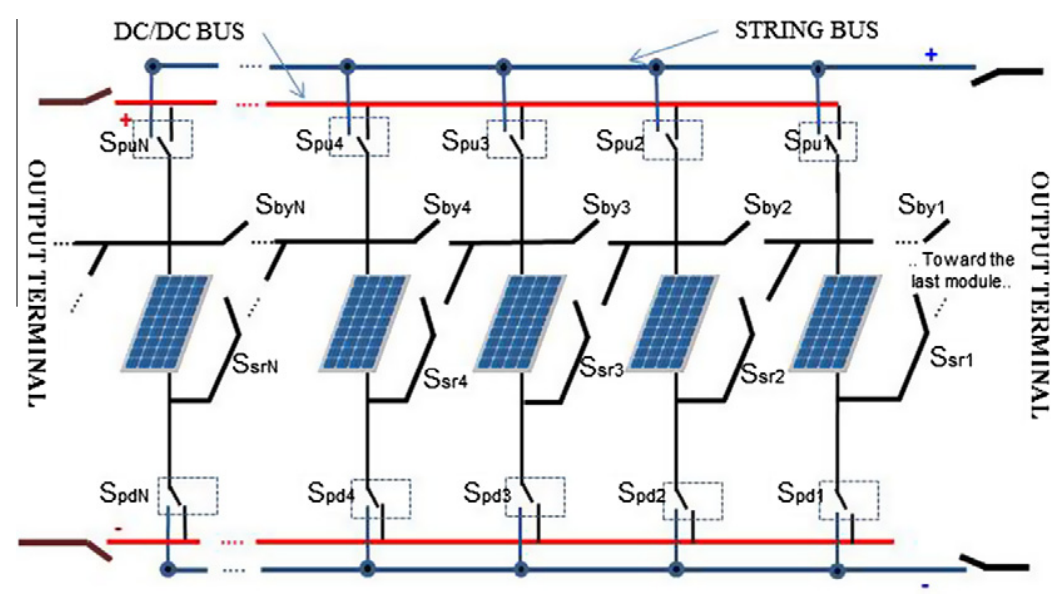

Fig. 3. Elastic PV structure. 
example, the system consists of three strings with three modules in each string; 40 switches; two string-buses to connect the MPV strings to the central inverters; and two DC/ DC-buses to connect the SPV modules to the DC/DC converter (if needed) during different operational conditions. The analysis used to describe the system's operation focuses on shading. The adaptive nature of the topology also applies to non-matched modules, faulty modules or other conditions that impedes the full operation of each module; hence reconfiguration occurs to optimize the efficiency of the overall system operation.

\subsubsection{Normal operation}

This operation case occurs when all PV modules are generating nominal power. The matrix will activate the required switches to form the complete MPV strings (three in this case) to connect to the inverter. The DC/DC converter is isolated and not utilizes in the normal operation condition. This configuration matches the distribution of the traditional central inverter shown in Fig. 1a.

\subsubsection{Two shaded modules}

For this condition, it is assumed that modules \# 1 and \# 7 of the original system are considered under shading conditions. In this case, there are seven remaining modules operating under normal conditions; hence the reconfigured

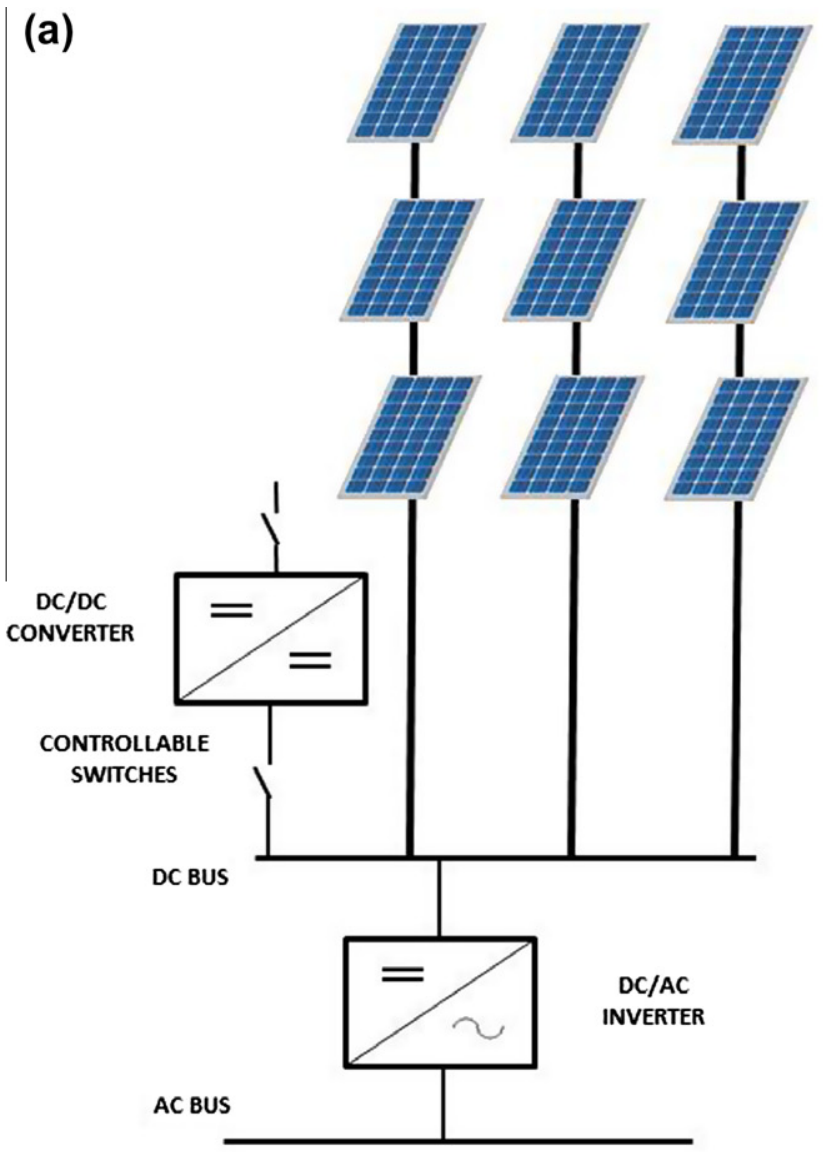

system will consist of two complete string modules (MPV) that will be connected directly to the inverter and one module in a partial string (SPV) connected to the inverter via the DC/DC converter. To accomplish this configuration, the series switches $S_{\mathrm{sr} 1}$ and $\mathrm{S}_{\mathrm{sr} 7}$ of the shaded modules, will open to isolate them from the other modules. At the same time, the bypass switches $S_{b y 1}$ and $S_{b y 7}$ will close to connect the adjacent modules (modules 6 and 8). Starting with the second module, a complete string is formed with modules \# 2, 3 and 4, and a second MPV is formed similarly. The parallel switches are activated when the MPV string is complete. Then, switches $S_{\mathrm{pu} 2}$ and $\mathrm{S}_{\mathrm{pd} 4}$ will activate in order to connect the first MPV string to the central inverter. This process will be applied to the second string by closing $S_{\text {pus }}$ and $S_{\mathrm{pd} 8}$. In this case, the array has one remaining module that does not meet the requirement for a complete a string. The matrix will consider this module as an SPV string and will connect it to the DC/DC-bus and DC/DC converter and finally to the central inverter using switches $S_{\text {pu9DC/DC }}$ and $\mathrm{S}_{\mathrm{pd} 9 \mathrm{DC} / \mathrm{DC}}$. Fig. $4 \mathrm{a}$ and $\mathrm{b}$ demonstrate this condition.

\subsubsection{Three shaded modules}

For this condition, it is assumed that modules \# 1, 5, and 8 of the original system are considered under shading conditions. In this case, there are six remaining modules operating under normal conditions; hence the reconfigured

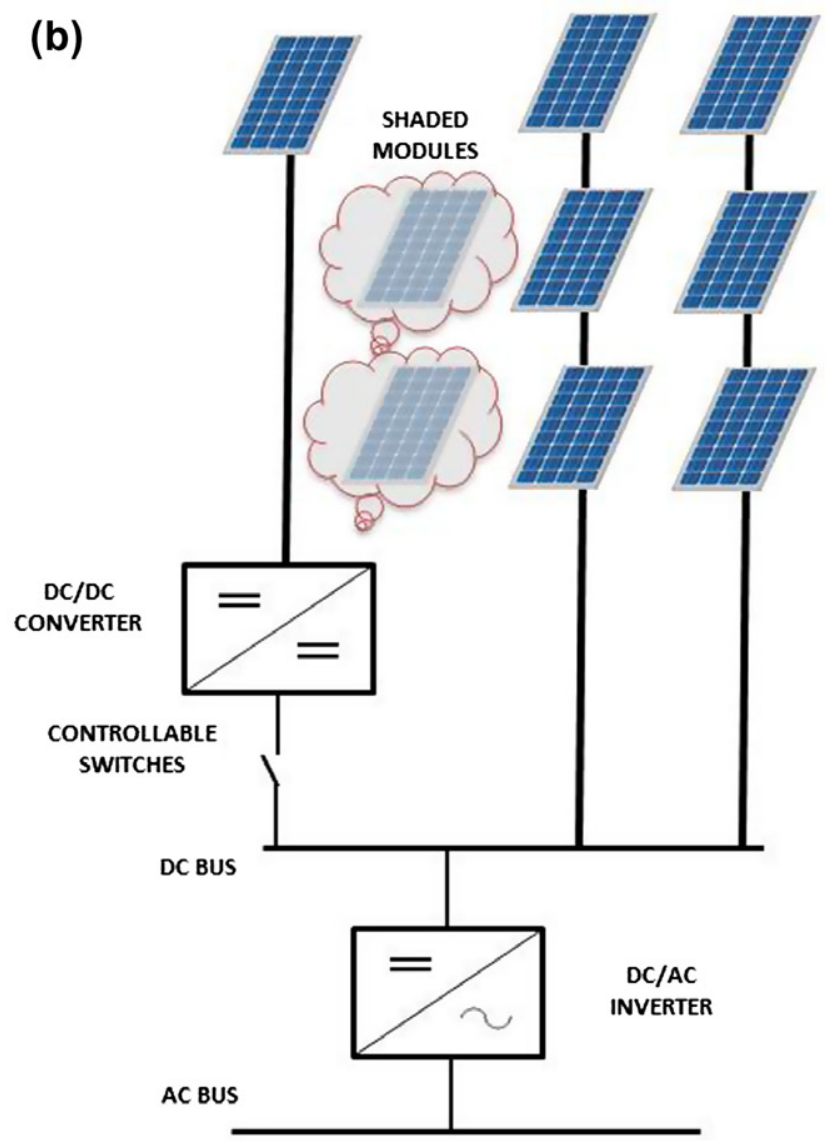

Fig. 4. EPVS illustration. (a) Illustrated EPVS operation during normal conditions. (b) Illustrated EPVS operation during two shaded modules. 
system will consist of two complete string modules (MPV) that will be connected directly to the inverter and no partial string requiring the use of the DC/DC converter. The series switches $\mathrm{S}_{\mathrm{sr} 1}, \mathrm{~S}_{\mathrm{sr} 5}$, and $\mathrm{S}_{\mathrm{sr} 8}$ of the shaded modules will open. The bypass switches, $S_{\text {by1 }}, S_{\text {by5 }}$, and $S_{\text {by } 8}$ will close to form MPV strings without shaded modules. The nonadjacent modules are then connected in series using $\mathrm{S}_{\mathrm{by} 5}$ and $\mathrm{S}_{\text {by } 8}$, i.e. modules number 7 and 9 will be connected in series. The parallel switches will close when the matrix forms an MPV string. Switches $\mathrm{S}_{\mathrm{pu} 2}, \mathrm{~S}_{\mathrm{pd} 4}$ of the first string and $\mathrm{S}_{\mathrm{pu} 6}, \mathrm{~S}_{\mathrm{pd} 9}$ of the second string will be activated. In this case, the array does not have any remaining modules that meet the requirements of the neither MPV string nor SPV string. Therefore, since no SPV string can be formed in the matrix, the DC/DC converter will not be used.

\subsection{Power management (control system)}

The Power management for the adaptive system is illustrated by the flow chart in Fig. 5. The operation of the system contains two functions represented as loops in Fig. 5. The left loop is responsible for identifying the condition of each PV module. This is accomplished by measurement of the module's parameters (current, voltage, temperature). Under normal operating conditions, the system will configure the modules in the normal MPV strings configuration and no SPV string will be formed inside the matrix. In shading/fault operation, the system will isolate the affected module(s) and reconfigure the remaining modules to form MPV and SPV strings as required for optimal operation. In order to optimize the configuration, each module is

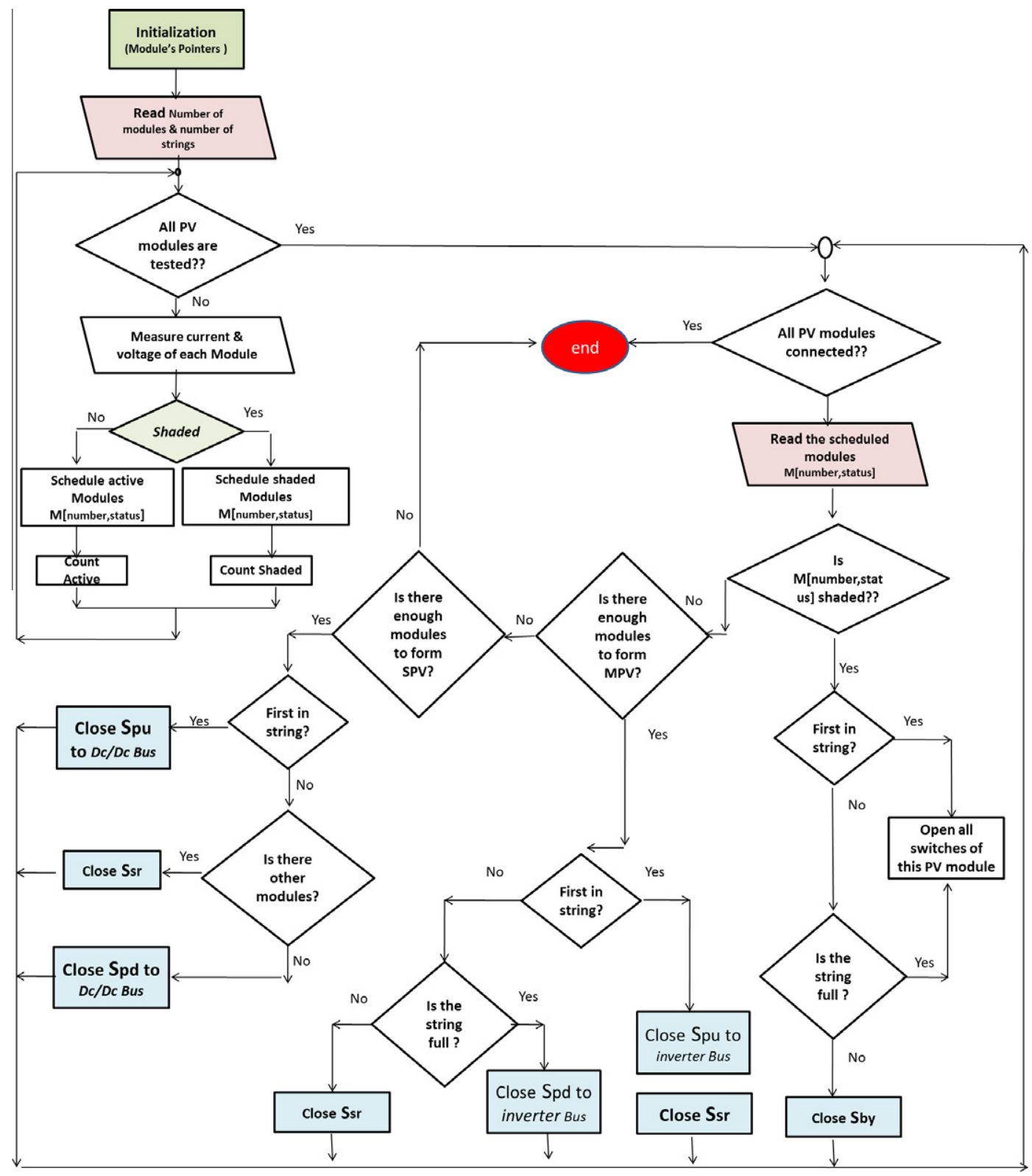

Fig. 5. Power management and control flow chart. 


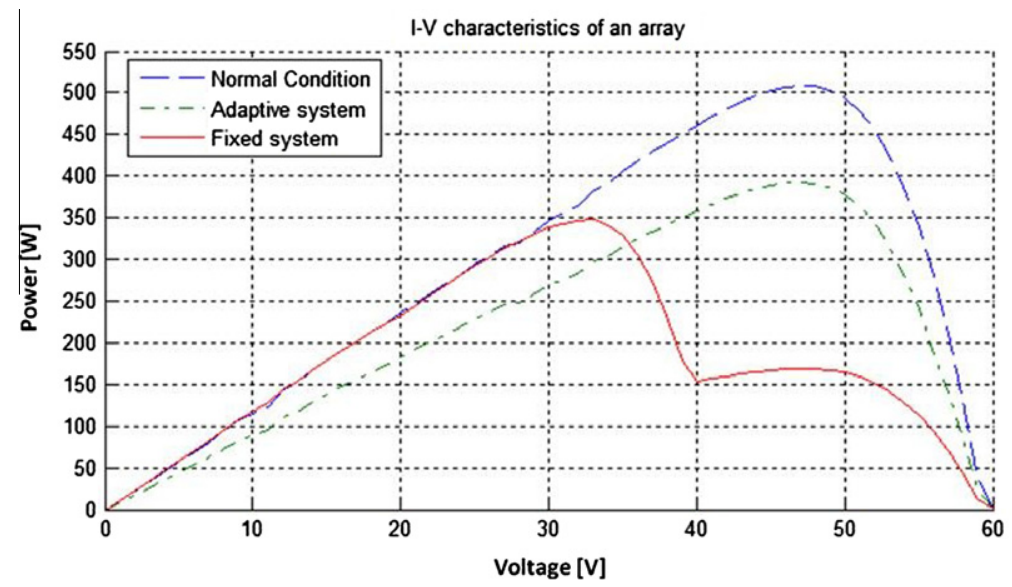

Fig. 6. Simulation result for two-shaded module.

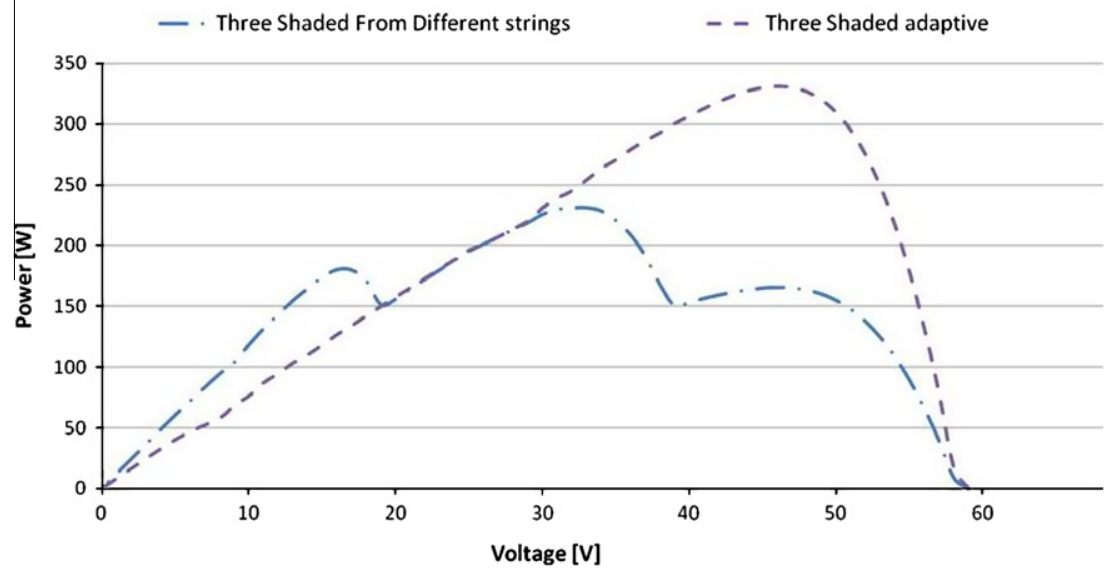

Fig. 7. Simulation result for three-shaded module.

examined with respect to its location in the string. Pointers are used to identify the location of each module in the string i.e. $M_{\text {[number, status] }}$. For example, if the first module is not-shaded, it is scheduled as $M_{[1, \text { active] }}$. This information is then used to form the connection and location in the strings. This process continues by examining the next module to determine the connection order; and track the number of modules in each MPV string. Once all the MPV strings are formed, if there are any remaining modules, an SPV string will be formed. The logic of the controller is illustrated for this point of the research. The actual controller design and implementation will be considered in future work.

\section{Verification methodology}

The proposed topology is modeled, analyzed and simulated to discuss it is benefits and to provide a comparison to the traditional central inverter topology. Furthermore, a prototype system has been designed and built. The results will be explained and analyzed in the following subsections. The analysis is based on the fact that the switches are modeled as ideal switches, with no losses across them. In general, Relays and contactors will be employed. These devices are based on contacts that will not have any losses. However, the control circuit to activate them will consume energy and this will be the losses that need to be incorporated as part of the management system losses.

\subsection{Modeling and PV system simulation}

A 4-parameter model is used to simulate the performance of PV cells. To use this model, manufacturers of PV modules provide the open circuit voltage, short circuit current, maximum power point power and associated voltage and current at standard test conditions (STC). STC are reference temperature, irradiance and air mass. This information is used to simulate the Current-Voltage $(I-V)$ and Power-Voltage $(P-V)$ curves. The current in the equivalent circuit of the PV cell can be expressed as a function of the module output voltage per Eq. (2).

$I_{\text {tot }}=I_{L}-I_{0}\left[\exp \left(\frac{e\left(V-I_{\text {totRs }}\right)}{A k T}\right)-1\right]-\left(\frac{V-I_{\text {tot }} R s}{R_{p}}\right)$

where $I_{t o t}$ is the total current of the real PV cell including all losses in the diode and the shunt resistor $R_{p}, A$ is the 
ideality factor, usually $=1, R s$ is the series resistor in the cell, $I_{0}$ is the saturation current of the diode, $e$ is the elementary charge $1.6 \times 10^{-19} \mathrm{C}, k$ is a constant of value $1.38 \times 10^{-23} \mathrm{~J} / \mathrm{K}, T$ is the cell temperature in Kelvin, and $V$ is the measured cell voltage (Tiwari and Dubey, 2010).

A new approach to simulate $I-V$ and $P-V$ curves is proposed in Kheswa (2004) and Saiju (2008) using a scale level approach. The scale is adaptable to the cell, module, or array level. Using the module's parameters, the model simulates the performance under normal operating conditions. However, it does not simulate PV system with different operational condition such as shadowing effect across some modules in the string or parallel strings with different operation conditions. To overcome limitation, another simulation model, (the model used in this work), is developed in Patel and Agarwal (2008). The model is based on a group concept. This allows simulating the real array cases of different isolation and shadowing effects. The inputs of each group are adjustable. Solar irradiance, temperature, and the number of parallel strings in each group are considered as inputs. Shaded modules are also considered in this case. The group concept is used to simulate our proposed adaptive system as described next.

\subsubsection{Simulation result}

The adaptive PV system is simulated in Matlab environment using the simulation model discussed in Patel and Agarwal (2008). A nine module system is developed and modeled for comparison between the proposed adaptive system and the traditional fixed central inverter PV system under varying operational conditions. Under normal operational conditions, the simulation curves of both systems are identical because of the identical configuration. During shading conditions, the case of dissimilar irradiance across the PV field that occurs because of moving thick clouds, trees, or any adjacent structure that makes a full shadow, cases of one, two thru eight shaded PV modules have been simulated and compared. Figs. 6 and 7 show the comparison results for two and three shaded modules. In addition, Table 1 provides a summary of the results for all simulated cases.

The case for two non-adjacent modules under shading is considered for further discussion. The results are show in Fig. 6. The fixed central inverter system has two shaded modules from different strings that activate the bypass diodes and generate multiple peaks. However, the adaptive system reconfigures the modules in MPV and SPV strings to improve the system performance and efficiency. As can be seen in Fig. 6, the adaptive system has a single peak whereas the fixed system has two peaks. The value of each peak is still lower than the peak generated by the adaptive system. The efficiency improvement for the adaptive system can be calculated using $\eta=\left(\mathrm{MPP}_{\text {fixed }} / \mathrm{MPP}_{\text {adaptive }}\right)$. The results show a $13 \%$ efficiency improvement. However, for this calculation, the DC/DC efficiency is assumed to be unity. In practicality, this efficiency will be based on one module connected to the DC/DC converter.

The case of three shaded modules under shading is also considered for further discussion. For this case, there are three possibilities. The first possibility is all shaded modules from one string, so a complete string is removed. In this case there is no efficiency improvement between the fixed and adaptive system. The results are shown in Fig. 7. The second possibility is one shaded module from each string. In this case the fixed system will have lower voltage value for each string, but same value. However, the adaptive system will form two complete strings with three modules in each string. In this case, the fixed and adaptive systems, will have a single peak at different levels, with more energy capture realized using the adaptive system. This is due to the fact that nominal DC voltage of the inverter is preserved, while in the fixed central inverter, the voltage is reduced in each string and the inverter will operate at lower efficiency. The third possibility is two

Table 1

Comparison between fixed and adaptive PV system for different shading conditions.

\begin{tabular}{|c|c|c|c|c|}
\hline \multirow{2}{*}{$\begin{array}{l}\text { Number } \\
\text { of } \\
\text { shaded } \\
\text { modules }\end{array}$} & \multicolumn{2}{|l|}{ System topology } & \multirow{2}{*}{$\begin{array}{l}\text { Simulation efficiency } \\
\text { improvement }=\left(P_{\mathrm{adv}}-P_{\mathrm{fx}}\right) / \\
P_{\mathrm{fx}}\end{array}$} & \multirow[t]{2}{*}{ Notes } \\
\hline & $\begin{array}{l}\text { Number of modules } \\
\text { connected to sub-PV string } \\
\text { (SPV) (DC/DC converter) }\end{array}$ & $\begin{array}{l}\text { Number of main PV strings } \\
\text { (three modules/MPV string) } \\
\text { (inverter input) }\end{array}$ & & \\
\hline 2 & 1 & 2 & $13 \%$ & \\
\hline 3 & 0 & 2 & 0 & Three shaded modules are from one string \\
\hline 3 & 0 & 2 & $43 \%$ & Three shaded modules are from different strings \\
\hline 5 & 1 & 1 & $31 \%$ & $\begin{array}{l}\text { One full shaded string and two shaded modules } \\
\text { from another string }\end{array}$ \\
\hline 6 & 0 & 1 & $0 \%$ & Two shaded strings \\
\hline 7 & 2 & 0 & $0 \%$ & $\begin{array}{l}\text { Two full shaded string and one shaded module } \\
\text { from another string }\end{array}$ \\
\hline
\end{tabular}


shaded module from one string and another shaded module from another string. In this case the adaptive system will have a $43 \%$ improvement over the fixed system as shown in Fig. 7. Note that with three shaded modules, the DC/DC converter will not be used.

\subsubsection{Efficiency comparison}

The efficiency results are shown in Table 1 . The traditional fixed PV system has more cases of shading because of the fixed connections between the modules. However, in order to compare both systems, the same shading cases across the PV modules are considered. The comparison does not include the actual efficiency of the DC/DC converter. The actual DC/DC efficiency will be included in the next section. As can be seen in Table 1, approximately $31 \%$ of the lost energy in the fixed configuration can be captured/generated using the proposed adaptive system during two shaded modules. This value is increased to $43 \%$ when three shaded modules as discussed earlier. The least performance improvement occurs when one or two modules are active and all other modules are shaded (disconnected). In this case, the DC/DC converter will ideally step up the voltage of the module(s) to match the inverter's required input voltage. There are multiple case studies with nine modules. The information in Table 1 provides the performance improvement for some selected cases. Because of all the possible cases, it is hard to provide a single efficiency improvement for the entire system. Improvement to each case is found based on the operation conditions.

\subsection{Prototype system design and development}

\subsubsection{The prototype set}

A prototype system has been designed and built to validate the proposed system and efficiency results as shown in Fig. 8a. The system consists of Nine PV modules connected in three parallel strings with three modules in series in each string. Each module is rated at $1-\mathrm{W}$ and $6-\mathrm{V}$ at MPP. The $I-V$ curve for reach string and for the entire array is shown in Fig. 8b. The figure shows the characteristics of each string and validates the nearly identical parameters of the connected modules. A 3-A and 55-V DC/DC converter with adjustable output voltage level in range of $5-55 \mathrm{~V}$ is also used to determine the overall efficiency of the system. In addition, bypass diodes for each module is implemented. To determine the $I-V$ characteristic, variable resistive loads are employed. The experiment is conducted in Omaha, NE, USA during the first week of November 2010. The experiments conducted in a sunny and clear sky conditions. Shading of modules is used for one, two thru eight modules to develop results to validate the simulation results.

\subsubsection{Results and analysis}

Fig. $8 \mathrm{c}$ shows the experimental results of the prototype system for two-shaded modules in the fixed and adaptive configuration. As can be seen in the figure, the results of the experimental and simulated systems are very similar. The captures multiple peaks for the fixed system are due to the bypass diodes. Similarly, Fig. 9a-c shows the results
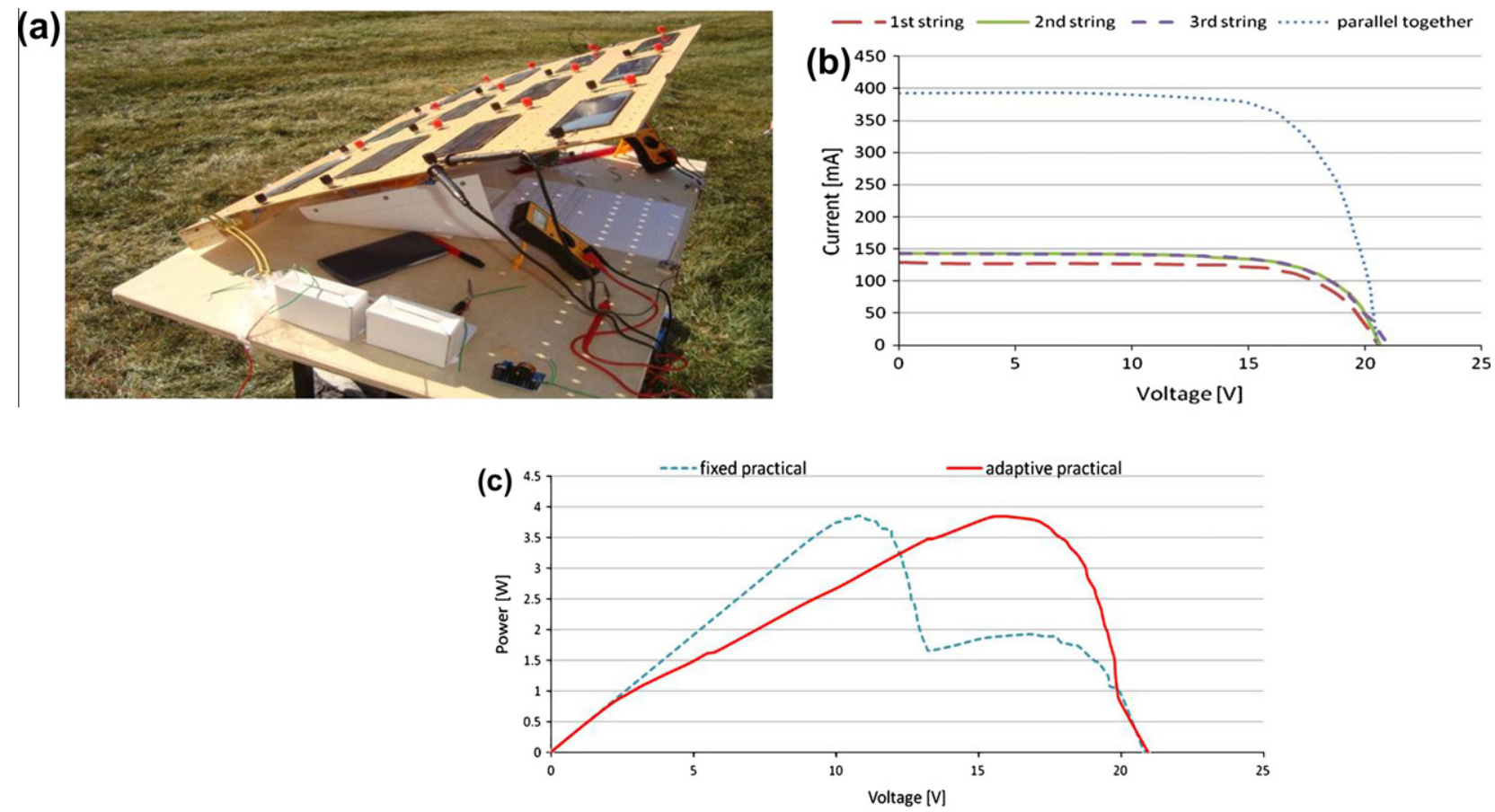

Fig. 8. Prototype board and experimental result. (a) Experimental prototype board. (b) $I-V$ curve of each string and the entire array. (c) $I-V$ curve for two-shaded modules for the fixed and adaptive system. 

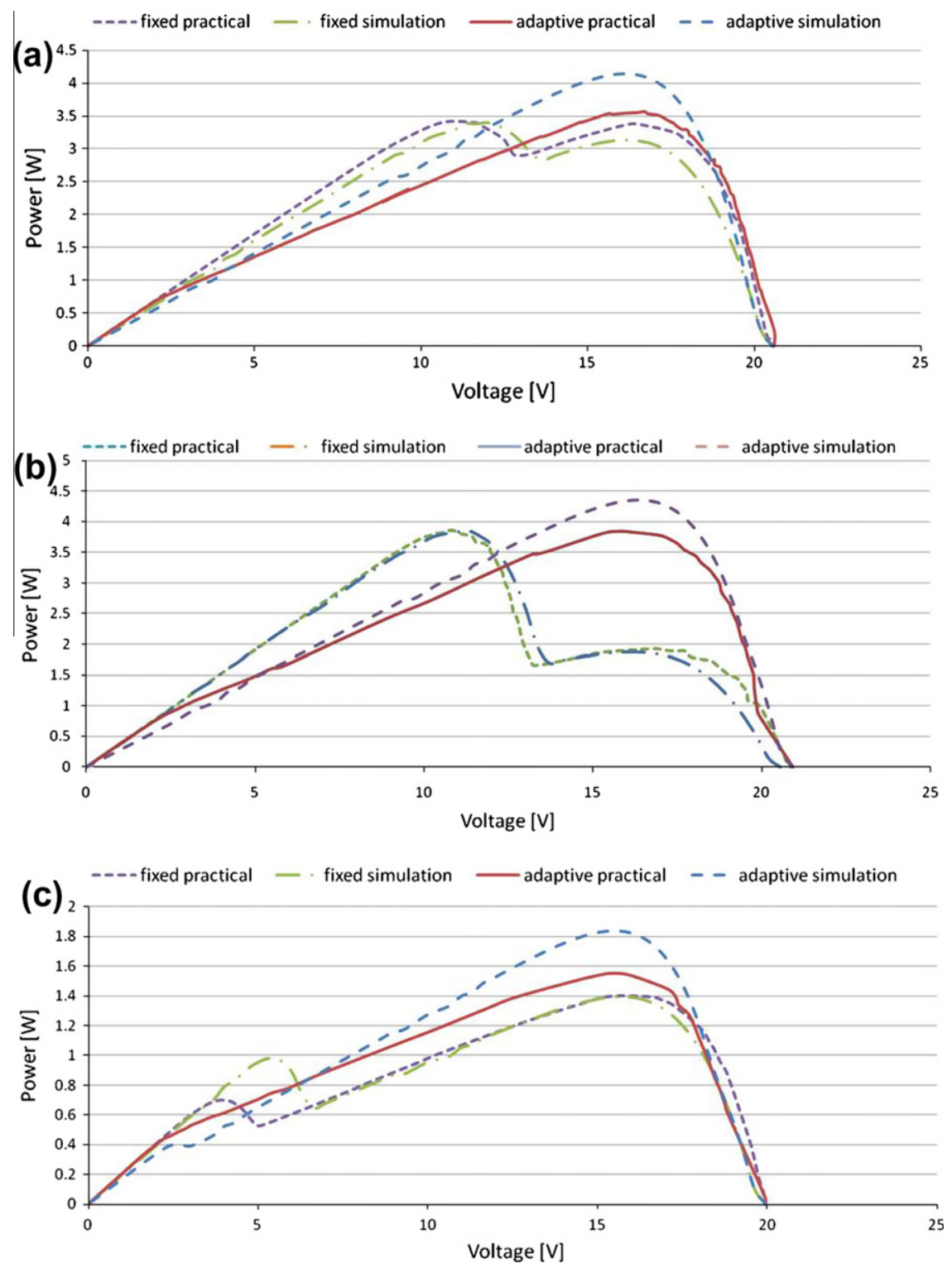

Fig. 9. Simulation and experimental results for one, two, and five shaded modules. (a) Simulation and experimental results for one shaded module. (b) Simulation and experimental results for two shaded modules. (c) Simulation and experimental results for five shaded modules.

for the fixed and adaptive system for one, two and five shaded modules respectively. Again, the results validate the simulated data and demonstrate the improvements in energy capture when the adaptive system is utilized.

Table 2 shows a comparative study of the overall efficiency between the simulation and the prototype results for different operational conditions. The comparison includes the actual efficiency of the DC/DC converter obtained from the manufacturer/published or common data. The simulation results showed that the maximum energy capture in the adaptive system occurs when five nonadjacent modules are shaded. In this case, the DC/ DC converter efficiency will reduce the energy capture from one module. The reason for this is that the DC/ DC is only responsible for one module while the other three remaining modules are configured in a string and are connected directly to the inverter. The minimal effi- ciency in the adaptive system occurs when a complete string is not available ( 7 or 8 modules shaded). In this case, the overall efficiency of the system will decrease as the actual DC/DC efficiency. However this case will still generate efficiency improvement over the fixed system. Although the prototype results for the output power curves match the curves generated using the simulation results, a reduction in the output power in the prototype curves is present. This is due to the efficiency of the real DC/DC converter which varies between $80-85 \% \pm 5 \%$ of the power rating size of the DC/DC converter as shown in Fig. 10a. Finally, Fig. 10b illustrates the efficiency improvement comparisons between the simulation and prototype results for both systems during different shading conditions with the DC/DC converter. The simulation and prototype results validate the proposed adaptive system and its improved energy capture. 
Table 2

Comparison between Simulation and experimental results of adaptive system for different shading conditions.

\begin{tabular}{|c|c|c|c|c|}
\hline \multirow{2}{*}{$\begin{array}{l}\text { Number of } \\
\text { shaded } \\
\text { modules }\end{array}$} & \multicolumn{2}{|l|}{ System topology } & \multirow{2}{*}{$\begin{array}{l}\text { Simulation efficiency } \\
\text { improvement }=\left(P_{\mathrm{adv}}-P_{\mathrm{fx}}\right) / \\
P_{\mathrm{fx}}(\%)\end{array}$} & \multirow{2}{*}{$\begin{array}{l}\text { Practical efficiency } \\
\text { improvement }=\left(P_{\mathrm{adv}}-P_{\mathrm{fx}}\right) / \\
P_{\mathrm{fx}}(\%)\end{array}$} \\
\hline & $\begin{array}{l}\text { Number of modules connected to } \\
\text { sub-PV string (SPV) (DC/DC } \\
\text { converter) }\end{array}$ & $\begin{array}{l}\text { Number of main PV strings (three } \\
\text { modules/MPV string) (inverter } \\
\text { input) }\end{array}$ & & \\
\hline 1 & 2 & 2 & 22 & 5 \\
\hline 2 & 1 & 2 & 13 & 0 \\
\hline 5 & 1 & 1 & 31 & 11 \\
\hline
\end{tabular}

\section{Conclusions}

A novel adaptive utility interactive PV system is proposed to increase the efficiency of the central inverter configuration. This is achieved by implementing a flexible switch matrix and one additional DC/DC converter. The proposed system consists of a single inverter; single DC/ DC converter and controllable elements. This approach uses less number of components than all the other topologies presented with the exception of the central inverter. However, the benefits realized from the increased energy harvested during the life of the system will offset the additional cost of the added components. The system is reconfigured in real-time to in response to operational conditions such as shading, soiling, mismatches, and module failure among others. The system has been validated under shading effects using a simulation and prototype system design. A comparison between the traditional fixed PV system and the proposed adaptive system is given. The results of this study indicate that the proposed system improves the sys-
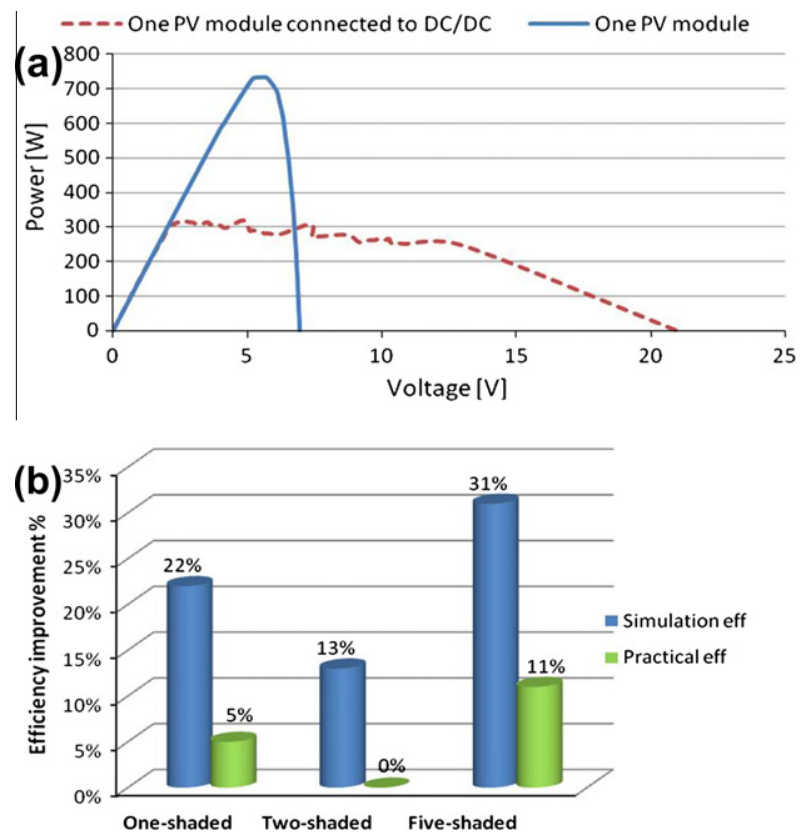

Fig. 10. Efficiency improvement comparison between simulation and practical results for different shading conditions with DC/DC response for one module. (a) DC/DC converter operation for one module. (b) Efficiency improvement comparison between simulation and practical results. tem efficiency under differing operational conditions by tracking the optimal configuration of each component. Preliminary results show that an average of $13 \%$ of the lost energy during shading can be recovered using this system. Research to develop an exact control approach as well as a related feasibility study is currently in progress.

\section{Acknowledgment}

This project is funded and sponsored by the United States Environmental Protection Agency (EPA).

\section{References}

Alahmad, M., Hess, H., 2008. Evaluation and analysis of a new solid-state rechargeable micro-scale lithium battery. IEEE Transactions on Industrial Electronics 55 (9), 3391-3401.

Alahmad, M., Hess, H., 2010. Microwave SOI based design of a power management system for JPL's rechargeable micro-scale batteries. Journal of Institution of Engineering and Technology (IET) Circuits, Devices \& Systems 4 (3), 261-268.

AlRashidi, M.R., AlHajri, M.F., El-Naggar, K.M., Al-Othman, A.K., 2011. A new estimation approach for determining the $I-V$ characteristics of solar cells. Solar Energy Journal 85, 1543-1550.

Auttawaitkul, Y., Pungsiri, B., Chammongthai, K., Okuda, M., 1998. A method of appropriate electric array reconfiguration management for photovoltaic powered car. In: The 1998 IEEE Asia-Pacific Conference on Circuits and Systems (APCCAS 98), Chiang, November 1998, pp. 201-204.

Beringer, S., Schilke, H., Lohse, I., Seckmeyer, G., 2011. Case study showing that the tilt angle of photovoltaic plants is nearly irrelevant. Solar Energy Journal 85, 470-476.

Chaaban, M.A., Alahmad, M., 2010. Adaptive photovoltaic system. In: IECON'2010 The 36th IEEE-IES's Annual Conference, November 710th, Phoenix, AZ.

Chang, C., 2003. Solar cell array having lattice or matrix structure and method of arranging solar cells and panels. US Patent 6635817 , October 21, 2003.

Chew, K.W.R., Siek, L., 2010. Single inductor quad-input-dual-output buck converter for photovoltaic systems. In: IECON'2010 The 36th IEEE-IES's Annual Conference, November 7-10th, Phoenix, AZ.

Dunlop, James P., 2010. Photovoltaic systems. In: Partnership with NJATC, second ed. American Technical Publishers, Inc., Orlan Park, Illinois, pp. 102-110.

Esram, T., Chapman, P.L., 2007. Comparison of photovoltaic array maximum power point tracking techniques. IEEE Transactions on Energy Conversion 22 (2).

Kheswa, Elias F.M., Davidson, Innocent E., 2004. Model of a Photovoltaic Fuel-Cell Generator. IEEE AFRICON 2004.

Kjaer, S.B., Pedersen, J.K., Blaabjerg, F., 2005. A review of single-phase grid-connected inverters for photovoltaic modules. IEEE Transactions on Industry Applications 41 (5). 
Lalonde, Louis, 2011. Don't Judge A Solar PV System's Efficacy By Inverter Efficiency Alone. Electronic Design Europe, October 25, 2011.

Li, Shuhui, Haskew, Timothy A., Li, Dawen, Hu, Fei, 2011. Integrating photovoltaic and power converter characteristics for energy extraction study of solar PV systems. Renewable Energy Journal 36, 3238-3245.

Massi Pavan, A., Mellit, A., De Pieri, D., 2011. The effect of soiling on energy production for large-scale photovoltaic plants. Solar Energy Journal 85, 1128-1136.

Myrzik, J.M.A., Calais, M., 2003. String and module integrated inverters for single-phase grid connected photovoltaic systems - a review. In IEEE Bologna Power Tech Conference, June 12th-26th, Bologna, Italy.

Nguyen, D., Lehman, B., 2008. An adaptive solar photovoltaic array using model-based reconfiguration algorithm. IEEE Transaction on Industrial Electronics 55 (7).

Patel, H., Agarwal, V., 2008. MATLAB-based modeling to study the effects of partial shading on PV array characteristics. IEEE Transactions on Energy Conversion 23 (1)

PVWatts Online Derate Calculator. $<$ http://rredc.nrel.gov/solar/calculators/PVWATTS/version1/derate.cgi $>$ (accessed 11.08.11).

Rashid, Muhammad, H., 2007. Power Electronics Handbook, second ed. Academic Press is an Imprint of Elsevier, Burlington, MA, USA, pp. 676-698.
Razykov, T.M., Ferekides, C.S., Morel, D., Stefanakos, E., Ullal, H.S., Upadhyaya, H.M., 2011. Solar photovoltaics electricity: current status and future prospects. Solar Energy Journal 85, 1580-1608.

Saiju, Rajesh, 2008. Hybrid power system modeling-simulation and energy management unit development. A Dissertation in Candidacy for the Degree of Doctor in Engineering.

Salameh, Z.M., Liang, C., 1990. Optimum switching point for array reconfiguration controllers. In: IEEE 21st Photovoltaic Specialists Conference, (21st PVSEC), vol. 2, Kissimmee, May 1990, pp. 971-976.

Saloux, Etienne, Teyssedou, Alberto, Sorin, Mikhail, 2011. Explicit model of photovoltaic panels to determine voltages and currents at the maximum power point. Solar Energy Journal 85, 713-722.

Sherif, R.A., Boutros, K.S., 2002. Solar module array with reconfigurable tile. US Patent 6350 944, February 26, 2002.

Tiwari, G.N., Dubey, S., 2010. Fundamentals of Photovoltaic Modules and Their Applications. Royal Society of Chemistry, Cambridge.

Velasco, G., Guinjoan, F., Piqué, R., Román, M., Conesa, A., 2009. Electrical PV array reconfiguration strategy for energy extraction improvement in grid-connected PV systems. IEEE Transactions on Industrial Electronics 56 (11), 4319-4331, ISSN: 0278-0046.

Zhu, Xue-Gui, Fu, Zhi-Hong, Long, Xing-Ming, Xin-Li, 2011. Sensitivity analysis and more accurate solution of photovoltaic solar cell parameters. Solar Energy Journal 85, 393-403. 